\title{
A new anatomical variation of the musculocutaneous and the median nerve anastomosis
}

\author{
M. Radunovic, A. Vukasanovic-Bozaric, N. Radojevic, T. Vukadinovic \\ Faculty of Medicine, University of Montenegro, Podgorica, Montenegro \\ [Received 23 December 2012; Accepted 12 February 2013]
}

\begin{abstract}
Variations of the brachial plexus and its terminal branches are not uncommon. Therein, the anatomical variations of the musculocutaneous and the median nerve are classified into 5 types, while the communicating branches between the musculocutaneous and the median nerve are classified into 3 types, depending on their position related to the coracobrachial muscle. The case reviewed in this paper presents a variation similar to that of the second variety, but is significantly different due to the appearance of the proximal musculocutaneous nerve and its communicating branching, the site rising from the communicating branch (through the coracobrachial), and important clinical implications of this new variation. Despite the communicating branch being located in the upper third of the upper arm, it should not be considered as being a double lateral root of the median nerve. (Folia Morphol 2013; 72, 2: 176-179)
\end{abstract}

Key words: musculocutaneous nerve, median nerve, anastomosis, communicating branch, anastomotic branch

\section{INTRODUCTION}

Variations of the brachial plexus and its terminal branches are not uncommon. Anastomosis between the musculocutaneous (MCN) and the median nerve (MN) are certainly the most common and frequent variations observed among the branches of the brachial plexus [6, 14]. Many papers in the literature have demonstrated that variations in brachial plexus branching have implicating clinical and surgical importance [3, 8, 10, 13].

Most commonly, the $\mathrm{MN}$, as a terminal mixed branch of the brachial plexus, is formed by its lateral and medial cord (the fasciculus lateralis et medialis). In the upper arm, the MN is situated medially to the coracobrachial muscle and MCN, running distally through the medial bicipital groove, and placed first laterally beside the brachial artery and veins. At the central part of the upper arm, the MN crosses the brachial artery and is placed medially against it [8]. Typically, the MN has no branches in the upper arm. If the MCN does exist, it is a terminal mixed branch of the lateral cord of the brachial plexus. The MCN is extended laterally to the MN, passing through the coracobrachial muscle, running distally between the biceps brachii and brachial muscle. It has 3 motor braches (for the coracobrachial, biceps brachii and brachial muscles) and ends with the terminal sensitive lateral cutaneous antebrachial nerve $[6,8,14]$. The MCN may be absent at all, and in such cases the MN contains all MCN's branches located in the upper arm [10].

Any anomalous pattern of the MCN and the MN is related to embryological development. Knowledge of such variations is important for surgeons to perform surgical procedures in the axillary region and in the upper arm [12]. The case under review here is directed

Address for correspondence: N. Radojevic, MD, Department of Forensic Medicine, Faculty of Medicine, University of Montenegro, Ljubljanska 1, Montenegro, 20000 Podgorica, tel: +382 69340 510, fax: +382 20412 283, e-mail: com_nr@yahoo.com 
toward such anatomical variations of nerve ends of the MCN and the MN.

\section{CASE REPORT}

A new variation, presented in the case under review here, was originally observed in the anatomical dissection of a male corpse who was 56 years of age. The corpse was preserved by injection of $4 \%$ formaldehyde in the femoral artery and underwent a year-long immersion in a formalin solution. After removing the skin and a section of the pectoral muscles, the brachial plexus and its terminal branches were located through the section of the right axilla and the upper arm in the anterior axillary line.

In the presented case (Fig. 1), the MN was characteristically formed by 2 roots, 1 by each lateral and medial cord of the brachial plexus. Proximally to the coracobrachial muscle, the MCN was presented as a single cord nerve. The communicating branch of the MCN was placed $8.2 \mathrm{~cm}$ after the lateral cord branching, inside its passage though the coracobrachial muscle. The joining site of the anastomotic branch and the MN was at the region of the lower pectoral major muscle's edge. The anastomotic branch was $5 \mathrm{~cm}$ in length. After this anastomotic branching, the MCN descended into standard motor branches for the biceps brachii and brachial muscle, as well as for the terminal sensitive nerve.

Further dissection of the axilla and the upper arm proved the motor and sensitive innervation of the upper arm to be normal. In the region of the presented variation, no arterial variations were observed.

\section{DISCUSSION}

The anastomotic branches are considered to be a congenital variation [3]. During embryogenesis, the formation of the upper limb is such that each myotome and dermatome maintains its own innervation. The muscles are developed from the mesenchyme during the $5^{\text {th }}$ week of intrauterine life, since the axons of spinal nerves grow distally, reaching the mesenchyme which represent the origin of the limb. Throughout this process, some of the nerves form tight connections to one another and subsequently join into specific variations. The variations of the arterial vessels seem to be one of the leading causes of anomalies and variations of the brachial plexus [3].

The upper limb buds are placed opposite the lower 5 cervical and upper 2 thoracic segments. During the buds' formation, the ventral primary rami of the

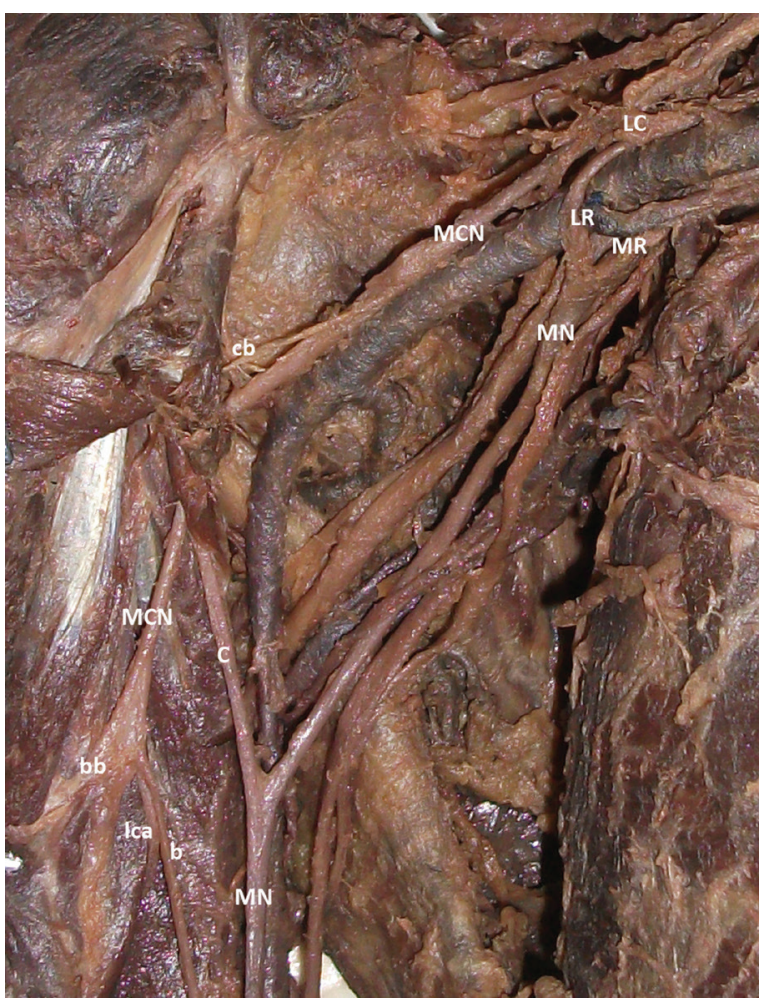

Figure 1. A new communicating branch between musculocutaneous and median nerve; $\mathrm{LC}$ - lateral cord of brachial plexus; $\mathrm{LR}$ - lateral root of median nerve; MR - medial root of median nerve; $\mathrm{MN}$ - median nerve; $\mathrm{MCN}$ - musculocutaneous nerve; $\mathrm{C}$ - communicating branch; $\mathrm{cb}$ - coracobrachial muscle branch; bb - biceps brachii muscle branch; Ica — lateral cutaneous antebrachial branch; $b$ - brachial muscle branch.

spinal nerves penetrate into the mesenchyme of the limb bud. Since the nerves enter the limb bud, close contact between them is formed and a differentiating mesodermal condensation is made. All of these processes leading to early contact between the nerve and muscle cells are an important condition for the functional differentiation $[11,12]$.

It is obvious that many factors during embryogenesis influence the formation of the upper arm's muscles and their nerves. They lead to such different types of variations in innervation. Significant variations in innervation patterns may be resulted by altered signalling between the mesenchymal cells and neuronal growth cones [1], or circulatory factors at the time of the fusion of the brachial plexus cords [9]. The limb muscles may develop from a locally originated mesenchyme, since the spinal nerves' axons grow distally to reach the target (muscle and skin) [5]. The appearance of a communicating branch may be originated by lacking of coordination between the formation of the limb muscles and their innervation. 


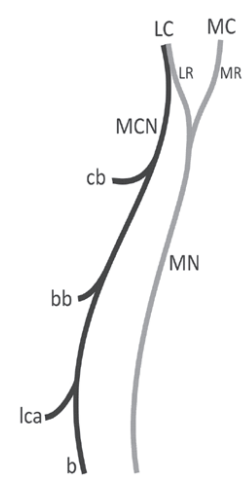

Type 1

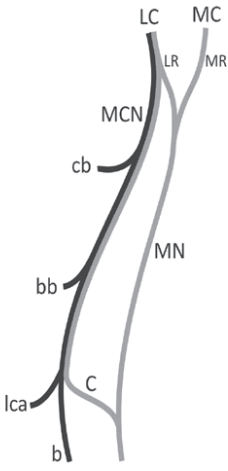

Type 2

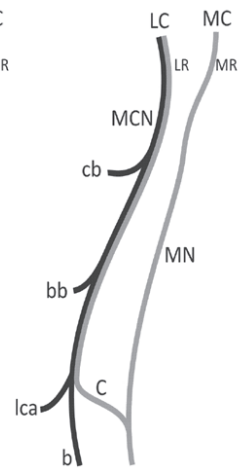

Type 3

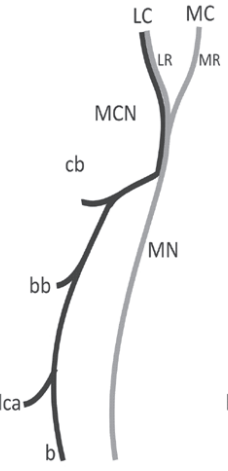

Type 4

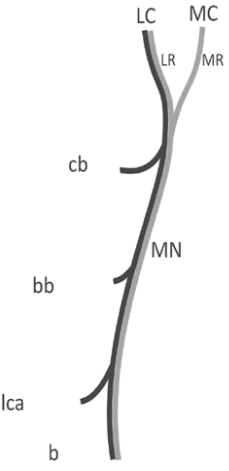

Type 5

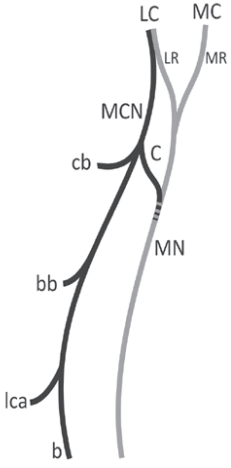

New

Figure 2. Variation of musculocutaneous and median nerve; see abbreviations in Figure 1.

Iwata's paper [7] shows that ventral segment of human brachial plexus gives the roots to the median and the ulnar nerves with the MCN arising from the median nerve. The author further maintains the possibility of the failure of differentiation as being a cause for some of the fibres taking an aberrant course into a communicating branch.

The anatomical variations of the MCN and the MN are classified into 5 types (Fig. 2) [2, 10]:

- Type 1: There are no communicating (anastomotic) braches between the MCN and the MN, the former of which passes through the coracobrachial muscle and has standard branches;

- Type 2: A part of the lateral root of the lateral cord is merged with the $\mathrm{MCN}$, and the communicating branch is joined to the $\mathrm{MN}$ in the distal section of the upper arm;

- Type 3: The whole lateral root of the MN is merged with the MCN and is distally joined to the MN;

- Type 4: The MCN is merged with the lateral root of the MN, then follows the MN for some distance, and finally separates from the MN as a lateral branch;

- Type 5: The MCN does not exist. The MN has all its MCN's branches located in the upper arm.

The communicating braches between the MCN and the MN may be classified as follows [4, 14]:

- Type I: The communicating branch is placed proximally to the coracobrachial muscle;

- Type II: The communicating branch is placed distally to the coracobrachial muscle;

- Type III: Neither the MCN, nor the communicating branch pass through the coracobrachial muscle.

The new variation, presented in the case, is morphologically similar to that of Type 2 ; still, some important differential distinctions do exist. Proximally to coracobrachial muscle, the MCN is a single cord nerve; therefore, the communicating branch is separated as a lateral branching, the same as any other of the MCN's distal branches. In the case reviewed by Kocabiyik et al. [8], the MCN is presented as 2 easy distinctive cords in the proximal section, out of which the medial cord separates as the communicating branch. However, in the case under presentation, the $\mathrm{MCN}$ does not consist of 2 cords. The communicating branch passes through the coracobrachial muscle, not proximally nor distally to it. From this point of view, the presented communicating branch should also be classified as a being a new Type IV of communicating branches between the MCN and the MN. Despite the fact that the communicating branch is located in the upper third of the upper arm [8], it is still unable to be considered as a double lateral root of the MN.

The presence of such a type of variation is clinically important for surgeons, orthopaedicians, and anaesthetists performing pain management therapies or regional anaesthesia to the upper limb [11]. Since the communicating branches between the MCN and the $\mathrm{MN}$ are very frequent, the evaluation of their presence is very important in traumatic injuries of the shoulder (most regularly, fractures and penetrating injuries). The injuries that affect the proximal section of the MCN may lead to weakness of the forearm flexors and thenar muscles. The communicating branch could explain the weakness of the flexors of the forearm and the upper arm in superior thoracic aperture syndrome $[3,13]$. The presented new variation herein entails an implicating importance related to the fractures of the coracoid process and proximal humerus, or anterior, descending, or medial luxation of the shoulder with consequent soft tissue injuries in the region of coracobrachial muscle (a contusion or laceration of the muscle), that can lead to a functional lesion 
of the MN in the forearm. Therefore, the presented variation should be especially taken into consideration during axillary lymph node dissection in cases of breast cancer.

\section{ACKNOWLEDGEMENTS}

Authors wish to thank Miodrag Radunovic, MD, $\mathrm{PhD}$, and Miroslav Stamenkovic, MD, PhD for advices and suggestions.

\section{REFERENCES}

1. Abhaya A, Bhardwaj R, Prakash R (2003) Dual origin of musculocutaneous nerve. J Anat Soc India, 52: 94.

2. Arora J, Kapur V, Suri RK, Khan RQ (2003) Inter-communications between median and musculocutaneous nerves with dual innervation of brachialis muscle. A case report. J Anat Soc India, 52: 66-68.

3. Beheiry EE (2004) Anatomical variations of the median nerve distribution and communication in the arm. Folia Morphol, 63: 313-318.

4. hauhan R, Roy TS (2002) Communication between the median and musculocutaneous nerve. A case report. J Anat Soc India, 51: 72-75.

5. Chiarapattanakom $P$, Leechavengvons $S$, Witoonchart K, Uerpairojkit C, Thuvasethakul P (1998) Anatomy and internal topography of the musculocutaneous nerve: the nerves to the biceps and brachials muscle. J Hand Surg, 23: 250-255.

6. Guerri-Guttenberg RA, Ingolotti M (2009) Classifying musculocutaneous nerve variations. Clin Anat, 22: 671-683.

7. Iwata H (1960) Studies on the development of the brachial plexus in Japanese embryo. Rep Dept Anat Mie Prefect Univ Sch Med, 13: 129-144.

8. Kocabiyik N, Yalcin B, Yazar F, Ozan H (2005) An accessory branch of musculocutaneous nerve joining median nerve. Neuroanatomy, 4: 13-15.

9. Kosugi K, Mortia T, Yamashita H (1986) Branching pattern of the musculocutaneous nerve. 1. Cases possessing normal biceps brachii. Jikeikai Med J, 33: 63-71.

10. Pacholczyk R, Klimek-Piotrowska W, Walocha J (2011) Absence of the musculocutaneous nerve associated with a supernumerary head of biceps brachii. A case report. Surg Radiol Anat, 33: 551-554.

11. Sadler TW (2006) Langman's medical embryology. In: Sadler TX ed. Muscular system. $10^{\text {th }} \mathrm{Ed}$. Lippincott Williams and Wilkins, Philadelphia, pp. 146-147.

12. Sawant SP, Shaikh ST, More RM (2012) Study of anastomosis between the musculocutaneous nerve and the median nerve. Int J Analyt Pharma Biochem Sci, 1: 37-43.

13. Uyaroglu FG, Kayalioglu G, Erturk M (2008) Anastomotic branch from the median nerve to the musculocutaneous nerve: a case report. Anatomy, 2: 63-66.

14. Venieratos D, Anagnostopoulou S (1998) Classification of communications between the musculocutaneous and median nerves. Clin Anat, 11: 327-331. 